\title{
Patterns in diel habitat use of fish covering the littoral and pelagic zones in a reservoir
}

\author{
Milan Ř́íha · Daniel Ricard · Mojmír Vašek • Marie Prchalová · Tomáš Mrkvička • \\ Tomáš Jůza $\cdot$ Martin Čech $\cdot$ Vladislav Draštík $\cdot$ Milan Muška $\cdot$ Michal Kratochvíl $\cdot$ \\ Jiří Peterka $\cdot$ Michal Tušer $\cdot$ Jaromír Sed'a $\cdot$ Petr Blabolil $\cdot$ Martin Bláha $\cdot$ \\ Josef Wanzenböck $\cdot$ Jan Kubečka
}

Received: 23 April 2014/Revised: 18 November 2014/Accepted: 24 November 2014/Published online: 3 December 2014

(C) The Author(s) 2014. This article is published with open access at Springerlink.com

\begin{abstract}
We investigated diel habitat use of fish covering the littoral and pelagic zones of the Rímov Reservoir (Czech Republic) and analyzed the influence of predator presence and of shifting feeding habitats in all dominant species and age groups. Our sampling revealed distinctive diel changes of fish distribution in the reservoir, which were age- and species-dependent. The overall abundance of subadult fish in littoral habitats was significantly higher at night than during the daytime. Subadults were almost absent in pelagic habitat during the day and their presence increased during the night, although densities were smaller than in the littoral. Adults preferred the pelagic zone during the day and partly migrated to the littoral at night. Potential fish predators were most likely
\end{abstract}

Handling editor: Odd Sandlund

Electronic supplementary material The online version of this article (doi:10.1007/s10750-014-2124-x) contains supplementary material, which is available to authorized users.

M. Říha · D. Ricard · M. Vašek · M. Prchalová .

T. Mrkvička $\cdot$ T. Jůza $\cdot$ M. Čech $\cdot$ V. Draštík ·

M. Muška · M. Kratochvíl - J. Peterka ·

M. Tušer · J. Sed'a · P. Blabolil · J. Kubečka $(\bowtie)$

Biology Centre AS CR v.v.i., Institute of Hydrobiology,

Na Sádkach 7, České Budějovice 370 05, Czech Republic

e-mail: kubecka@hbu.cas.cz

M. Říha · P. Blabolil

Faculty of Science, University of South Bohemia,

České Budějovice, Czech Republic responsible for small fish avoidance of the littoral and pelagic zones during day. Higher availability of food in the littoral was the most important driver of the high occurrence of subadults at night. Day preference of pelagic zone by adults is most likely caused by higher profitability of this habitat in comparison with littoral. The reasons for night inshore migration of adults are not obvious, but the homogenization of their distribution or resting in the littoral could explain such behavior.

Keywords Distribution - Diel dynamics · Predation · Feeding rate $\cdot$ Quantitative sampling

\section{Introduction}

Diel horizontal migration of fish between the littoral and pelagic zones is a well-documented phenomenon in European lentic waters (e.g., Bohl, 1980; Gliwicz \&

T. Mrkvička

Faculty of Economy, University of South Bohemia,

České Budějovice, Czech Republic

M. Bláha

Faculty of Fisheries and Protection of Waters, University of South Bohemia, České Budějovice, Czech Republic

J. Wanzenböck

Research Institute for Limnology, University of Innsbruck, Mondsee, Austria 
Jachner, 1992; Brabrand \& Faafeng, 1993; Copp \& Jurajda, 1993; Romare et al., 2003; Wolter \& Freyhof, 2004). Studies dealing with diel habitat shift predominantly focused on juvenile or small zooplanktivorous fish (e.g., Bohl, 1980; Gliwicz \& Jachner, 1992; Romare et al., 2003; Lewin et al., 2004; Hölker et al., 2007; Jůza et al., 2014) in which migration is driven by resource availability and also by the avoidance of predators (Bohl, 1980; Gliwicz et al., 2006). Generally, small fish are associated with submerged macrophytes or woody structures in the littoral during the day (Werner et al., 1983; Lewin et al., 2004; Gliwicz et al., 2006). Day shelters provide refuge that reduce predation pressure on small fish, but may also reduce small fish feeding rates due to limited resources in the vicinity of shelters (Gliwicz \& Jachner, 1992; Werner et al., 1983; Gliwicz et al., 2006). The predator-prey interaction is light-dependent such that upon a decrease in light intensity predator-avoidance effect of structures to predation risk is reduced (Cerri, 1983) and small fish could use habitats richer in food (mostly zooplankton) in the pelagic zone [often referred to as night offshore migration (NOM); Bohl, 1980; Romare et al., 2003; Gliwicz et al., 2006].

Contrary to this generally accepted pattern, the opposite migration, when fish move to the littoral zone at night, has also been documented and termed "night inshore migration" (NIM). Such behavior was particularly described for subadult and adult fish in rivers (Kubečka \& Duncan, 1998; Wolter \& Freyhof, 2004; Erös et al., 2008), some lakes (Schulz \& Berg, 1987; Zamora \& Moreno-Amich, 2002; Jacobsen et al., 2004) and reservoirs (Kubečka, 1993; Vehanen et al., 2005; Ř́ha et al., 2011). The reason for such migration is poorly understood and several different explanations have been proposed. Controversially, several authors assumed predator avoidance to be an important driving force for NIM. They explained that NIM takes place to avoid nocturnal offshore predators (Copp \& Jurajda, 1993; Jacobsen et al., 2004). Other explanations given for NIM are changing of feeding habitat or activity. Changes of feeding habitat was observed for adult common bream Abramis brama (L.) in Lake Constance, Switzerland, as they feed on zooplankton during the day in the pelagic zone and migrate inshore to feed on benthic prey at night (Schulz \& Berg, 1987). A change in activity was proposed for nocturnal feeders that forage prey predominantly at night (Wolter \& Freyhof, 2004;
Roach \& Winemiller, 2011) or for visual day foragers that use inshore habitats for resting (Zamora \& Moreno-Amich, 2002).

A previous study compared the diel changes of the fish assemblage in the unstructured littoral of four

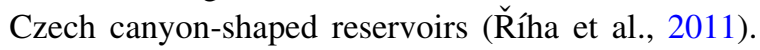
The results of this study clearly demonstrated that a large number of species perform diel habitat switch in these reservoirs. However, this study did not determine the source of habitats of migrants and both NOM and NIM migration patterns could be considered to explain observed changes. Beside questions to the dynamics of movements between littoral and pelagic

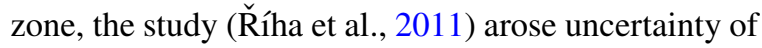
potential drivers behind diel habitat changes. The unstructured shallow littoral were occupied at night by species and size categories with wide range of foraging strategies, that ranged from day visual small zooplanktivorous feeders (e.g., small perch, Perca fluviatilis L., and roach, Rutilus rutilus (L.); Lewin et al., 2004) and predators (large perch; Zamora \& Moreno-Amich, 2002) through night bentic feeders (ruffe, Gymnocephalus cernua (L.); Jamet \& Lair, 1991) and predators [Sander lucioperca (L.), and eel, Anguilla anguilla (L.); Brabrand \& Faafeng, 1993; Prchalová et al., 2013] to species feeding in both periods (e.g., adults of bream; Schulz \& Berg, 1987). All the reasons mentioned above can presumably be causing diel habitat shift and could be considered as potential habitat switch drivers.

Only quantitative sampling of the structured and unstructured littoral as well as pelagic zone during both diel periods could provide information about the dynamics of subadult and adult fish spatial distribution over those periods (Wolter \& Freyhof, 2004). Such sampling could determine which species or size categories switch habitats according to the diel periods and how these species utilize these particular habitats. Moreover, such sampling could also reveal the occurrence of potential predators and evaluate their impact on the diel distribution dynamics of different species and size categories. In European freshwaters, studies dealing with diel changes of fish distribution largely focused on only one species (Schulz \& Berg, 1987; Zamora \& Moreno-Amich, 2002; Jacobsen et al., 2004) or sampling of a community in only one zone (Brosse et al., 2007; Erös et al., 2008). However, there is a very limited number of studies that performed simultaneous quantitative sampling of the 
whole fish communities in both zones and periods (Wolter \& Freyhof, 2004; Muška et al., 2013) and in our best knowledge there is no study providing picture of diel changes among all mentioned habitats simultaneously.

The present study evaluated diel changes of fish distribution within the canyon-shaped Rímov Reservoir because regular night migration into the unstructured littoral has been observed there (Kubečka, 1993; Říha et al., 2011). The unstructured and structured littoral habitats as well as the pelagic zone of the reservoir were quantitatively sampled during the summer of three consecutive years (2009-2011). The aims of the study were to (1) characterize diel changes of fish assemblage in the unstructured and structured littoral and pelagic habitats of the reservoir and compare observed diel patterns between the littoral and pelagic as well as establish their stability throughout the years; (2) determine the occurrence of potential predators in the mentioned zones in order to reveal potential fish avoidance of zones with higher concentration of their predators; (3) examine diel changes in the diet and consumption rate of dominant species in the littoral and pelagic zones, to reveal potential shifts of feeding habitat between day and night.

\section{Materials and methods}

Study site

The study was carried out in the canyon-shaped Rímov Reservoir (about $170 \mathrm{~km}$ south of Prague, $48^{\circ} 50^{\prime} \mathrm{N}$, $14^{\circ} 30^{\prime} \mathrm{E}$ ). The reservoir was built in 1978 by damming the Malše River. The maximum area of the Římov Reservoir is 210 ha and its maximum volume is $33 \times 10^{6} \mathrm{~m}^{3}$. The depth of the reservoir continuously increases from the tributary to the dam, where the maximum depth is $45 \mathrm{~m}$. The average depth is $16 \mathrm{~m}$. Further description of the reservoir is given in Říha et al. (2009). The reservoir is dimictic, with summer stratification usually lasting from May to September and with water transparency (Secchi depth) ranging between 0.75 and $1.5 \mathrm{~m}$ during the study period. The trophic status of the reservoir is mesotrophic to eutrophic, with phosphorus and chlorophyll-a concentrations decreasing steadily from the tributary to the dam (Sed'a \& Devetter, 2000; Rychtecký \& Znachor, 2011).
The littoral zone is without submerged aquatic macrophytes because of the steep banks and high water level fluctuations (Hladík \& Kubečka, 2003). Based on the bottom substrate and slope, four distinctive habitats can be distinguished in the reservoir inshore area (Kratochvíl et al., 2012) (I) beach (unstructured littoral) - bottom without any structures but with only a low occurrence of small boulders $(<20 \mathrm{~mm})$ and a gentle slope $\left(<10^{\circ}\right)$, length of shoreline (LS) represented by this habitat is $4,553 \mathrm{~m}$ and the proportion of this habitat from the total shoreline (PTS) is $22.07 \%$; (II) stumps (structured littoral)—bottom with gentle slopes $\left(<8^{\circ}\right)$ and remains of flooded terrestrial vegetation as stumps and branches (these bottom structures) cover app. 5-15\% of the bottom area in this habitat in the sampled reservoir section (Fig. 1), $\mathrm{LS}=1,659 \mathrm{~m}$ and PTS $=8.04 \%$; (III) rubble (structured littoral)bottom with large boulders $(>20 \mathrm{~mm})$, a higher slope $\left(30^{\circ}-35^{\circ}\right)$ and sporadic occurrence of stumps as well, $\mathrm{LS}=11,881 \mathrm{~m}$ and PTS $=57.59 \%$; and (IV) rocksrocky bottom with a vertical slope (up to $90^{\circ}$ ),

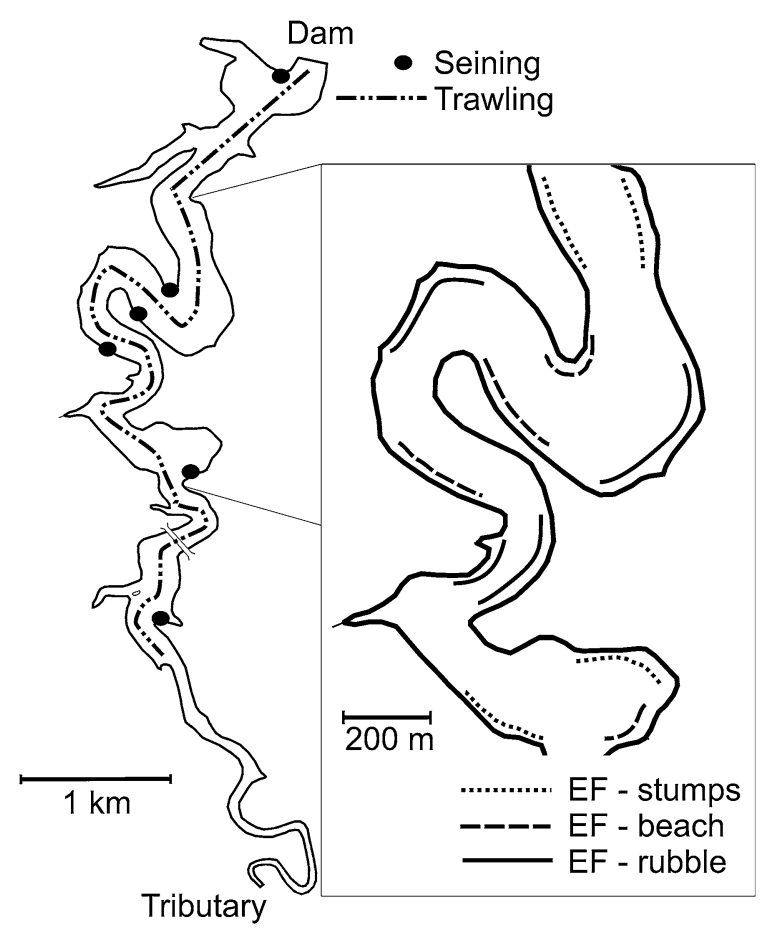

Fig. 1 Map of the Římov Reservoir, Czech Republic. Beach seining sites are indicated by black points. The dashed doubledotted line indicates the approximate path of the trawl. Electrofishing (EF) sites in the middle part of the reservoir are depicted separately; dotted line indicates stump habitat, dashed line beach habitat, and solid line rubble habitat 
$\mathrm{LS}=2,536 \mathrm{~m}, \quad \mathrm{PTS}=12.29 \%$. Habitat type IV (rocks) was not considered as a littoral habitat due to the vertical slope of the bank, and thus the sampling of rocky habitat was not performed.

The proportion of total area and volume of the pelagic zone (considering the upper $0-5 \mathrm{~m}$ of the water) and the inshore area ( $0-5 \mathrm{~m}$ depth) is 0.79 and 0.89 for the former and 0.21 and 0.11 for the latter. In other words, the pelagic zone represents a much larger habitat than the littoral zone in the reservoir.

Since 1989, the reservoir has had a s

table fish composition with a high dominance of cyprinids (Říha et al., 2009). The vertical distributions of dominant species follow oxygen/temperature stratifications in the summer period. The highest fish densities were found in the warm and well-oxygenated upper part of the water column (Čech \& Kubečka, 2002; Prchalová et al., 2009; Jarolím et al., 2010). As such, sampling of the upper water layer provides an appropriate measure of fish abundance, biomass and diversity since only a small proportion of fish are found in deeper waters.

Fish sampling

Fish sampling was performed in August of three consecutive years (2009-2011). Investigation of the unstructured littoral (beach habitat) was conducted by beach seining in the years 2009 and 2010, while all littoral habitats (beach, rubble, and stumps) were sampled by electrofishing (EF) in the year 2011. Such a combination of methods was chosen for several reasons. Beach seining gives very robust results with low biases in size/species selectivity (Pierce et al., 1990; Ř́ha et al., 2008). The two years of sampling using a beach seine net (2009-2010) provide solid data focusing on the temporal stability of migration to the unstructured littoral. However, beach seining cannot be used for sampling sites with structures on the bottom because of gear entanglement. Therefore, EF was used to reveal diel changes of fish assemblage among all littoral habitats (beach, stumps, and rubble). EF has higher selectivity for larger fish during the day than at night (Reynolds, 1996), although we assume that this bias in selectivity fails to affect our results substantially. EF provides at least a semi-quantitative estimate of fish density and reveal fish distribution trends throughout littoral habitats and periods (Pierce et al., 2001).
The beach seine net was used in the same manner as described in Říha et al. (2009). The net was $200 \mathrm{~m}$ long, $4 \mathrm{~m}$ high, and had a $10 \mathrm{~mm}$ (full mesh, knot center) mesh size. It was spread to create a rectangle from the shoreline to the open water (to isobaths of $3.5-4 \mathrm{~m}$ ), using a rowing boat. Seining was conducted at five sites (Fig. 1), two hauls were performed at each site and diel period in 2009 and only one haul was performed at each site and diel period in 2010.

EF was performed using a boat electrofisher system similar to that described by Miranda and Kratochvíl (2008). EF was conducted by steering the boat at slow speed along the shoreline and energizing a field within 5-7 $\mathrm{m}$ of the shoreline. EF was conducted during the day and night at 12 sites in the middle part of the reservoir in 2011 (Fig. 1). Four sites represented each habitat (beach, stumps, and rubble). The sampling trajectory at each site was recorded using a GPS receiver (Garmin GPSMAP 60CSx; Garmin International, Inc., Olathe, Kansas, USA) and the sampled distance calculated using the OziExplorer software (D\&L Software, Brisbane, Australia).

Pelagic sampling was performed using trawling and purse seining. Trawling was used during both diel periods, but Ríha et al. (2012) found that the trawl used in this study underestimates the density of bleak in the Římov reservoir at night. Therefore, the night trawl was accompanied by purse seining which is highly efficient for sampling bleak (Říha et al. 2012). Thus, the bleak night density estimates were obtained by purse seining, whereas those of other species were acquired using the trawl. Trawling was performed during the whole threeyear study period, but purse seining only in the years 2010 and 2011. Therefore, the bleak density estimate is not available for the year 2009 .

Surface pair trawling was conducted using a trawl opening width of 12-13.5 m, and an opening height of 8 m (detailed description given in Ríha et al., 2012). A GPS receiver (Garmin GPSMAP 60CSx) was fixed to each end of the head rope. GPS tracks of both ends of the head rope were used for the exact calculation of the sampled area of each haul. This parameter was calculated using the OziExplorer software. Two survey vessels with $64 \mathrm{HP}$ and $210 \mathrm{HP}$ engines were used to tow the trawl. The duration of one haul was between 10 and $25 \mathrm{~min}$ at the towing speed of $1-1.3 \mathrm{~m} \mathrm{~s}^{-1}$. Each year, sampling was performed from the dam to the upstream part of the reservoir (Fig. 1) during both diel periods. 
The purse seine net used had a length of $120 \mathrm{~m}$ and height of $12 \mathrm{~m}$ (detailed description given in Říha et al., 2012). The exact position of each haul was recorded with the Garmin GPS device during the setting of the net, and the area sampled was calculated with the OziExplorer software. Sampling was performed only during the night at the same sites as the trawling.

Day sampling by all mentioned sampling gears was conducted from 1100 hours-1700 hours and night sampling from 2300 hours-0300 hours. The total sampling effort achieved by all gears is summarized in Table 1.

Fish catches from all gears were identified to the species level, measured to the nearest $5 \mathrm{~mm}$ (standard length, SL). Catches of young-of-the-year (YOY) fish were ignored and only fish older than one year were considered for the study. Each sample was standardized before analysis to the same unit of area. The samples from beach seine, trawl and purse seine was expressed as the number of individuals per hectare, whereas the samples from $\mathrm{EF}$ as the number of individuals per $100 \mathrm{~m}$ of shoreline.

Table 1 Sampling effort carried out in both the littoral and pelagic zones during the study

\begin{tabular}{|c|c|c|c|c|c|}
\hline & \multirow{2}{*}{$\begin{array}{l}\text { Diel } \\
\text { period }\end{array}$} & \multirow[t]{2}{*}{ Habitat } & \multicolumn{3}{|l|}{ Year } \\
\hline & & & 2009 & 2010 & 2011 \\
\hline \multicolumn{6}{|l|}{ Littoral } \\
\hline \multirow{2}{*}{$\begin{array}{l}\text { Beach seining } \\
\text { (ha) }\end{array}$} & Day & Beach & 1.24 & 1.29 & - \\
\hline & Night & Beach & 1.24 & 1.24 & - \\
\hline \multirow{6}{*}{$\begin{array}{l}\text { Electrofishing } \\
\quad(\mathrm{m})\end{array}$} & Day & Beach & - & - & 1,125 \\
\hline & & Stumps & - & - & 920 \\
\hline & & Rubble & - & - & 1,400 \\
\hline & Night & Beach & - & - & 900 \\
\hline & & Stumps & - & - & 860 \\
\hline & & Rubble & - & - & 1,600 \\
\hline \multicolumn{6}{|l|}{ Pelagic zone } \\
\hline \multirow[t]{2}{*}{ Trawling (ha) } & Day & & 16.31 & 9.99 & 10.37 \\
\hline & Night & & 17.25 & 9.43 & 9.05 \\
\hline $\begin{array}{l}\text { Purse seining } \\
\text { (ha) }\end{array}$ & Night & & & 2.09 & 2.09 \\
\hline
\end{tabular}

Effort is expressed as the sampled area (hectares) for beach seining, purse seining and trawling and as the length of sampled shoreline for electrofishing (meters)
Ecospecies separation

Catches of dominant species such as bream, roach, and bleak from each gear were divided into different ecological roles based on size/age groups prior to statistical analysis. The division of these species into age categories was carried out using scale analysis to relate age and length. Scales of 60-110 individuals of each species in each year of the study were read using a microfiche reader (Indus 4601; magnification $\times 24$ ) and the age was determined by a standard method (Howland et al., 2004). The first category includes only fish of age $1+$ for bream, roach, and bleak (65-110 mm, standard length SL; herein referred as " $1+$ species"). The second includes middle size fish of age $2+$ to $4+(115-200 \mathrm{~mm}$ SL; herein referred as "middle species") in case of bream and roach and fish older than $1+$ in the case of bleak (herein referred as "large bleak"). The third group includes large fish older than 4+, defined only for bream and roach (>200 mm SL, herein referred as "large species").

Diet analysis and zooplankton sampling

Diet analysis was conducted to determine differences in the diet and in the fullness of digestive tract between the littoral and pelagic zones and diel periods. These data were collected for dominant species, namely, bream (included only $1+$ bream and large bream), roach (included 1+ roach and large roach), bleak (both size groups together), and ruffe. For diet analysis, subsamples of these species were taken from beach seine and trawl catches in both diel periods of the year 2009. Shortly after capture, the fish digestive tracts were dissected and preserved in a 5-10\% formaldehyde solution. In the laboratory, a gut fullness code from zero (empty) to five (fully distended) was assigned separately to the three loops of each intestine in the case of cyprinids and for each stomach and gut for ruffe. The percent composition of the diet by volume was estimated visually using a binocular microscope for each loop separately. Five categories of food were distinguished: zooplankton, insect larvae, insect adults, plant material/detritus, and other. When mucus or inorganic material (sand grains) was a component of the gut content, its share was assessed and subtracted from the gut fullness estimates.

The fish sampling was accompanied by zooplankton sampling. Zooplankton were found to be the main 
component of bream, roach, and bleak diet, especially the genus Daphnia, in the pelagic zone of the Rímov Reservoir (Vašek \& Kubečka, 2004; Vašek et al., 2003). Further, the availability of a Daphnia diet was suggested as a main driver of horizontal migration for small zooplanktivorous fish (Bohl, 1980; Romare et al., 2003; Gliwicz et al., 2006). Daphnia was sampled in the unstructured littoral (beach) and the pelagic zone in the year 2009 and in the pelagic zone and all littoral habitats (beach, stumps, and rubble) in the year 2011. In the littoral, samples were collected using a Schindler-Patalas sampler with a 301 volume (200 $\mu \mathrm{m}$ mesh size in the collector) from the middle of the water column, where the depth was approximately $1.0 \mathrm{~m}$. In the pelagic zone, vertical net hauls by plankton net (net diameter $20 \mathrm{~cm}$, mesh size $200 \mu \mathrm{m}$ ) were carried out through a $0-5 \mathrm{~m}$ depth stratum, which approximately corresponded to the extent of epilimnion during the study period where the majority of Daphnia are concentrated (Sed'a et al., 2007). Sampling was performed only during the daytime because no diel change was detected in Daphnia distribution in the pelagic zone of the Rímov Reservoir (Sed'a et al., 2007).

\section{Statistical analysis}

We first evaluated the diel differences in densities separately for the unstructured littoral habitat (sampled by beach seine), for all littoral habitats (sampled by EF), and for the pelagic zone (sampled by trawl and purse seine). Each habitat was sampled during the day and the following night. Beach seining, trawling and purse seining were conducted in multiple years, so a year effect must be included in order to properly estimate the diel differences. The catch data also contained many instances of zeroes (no catch of a given species in a given habitat and diel period) and must be evaluated in light of the fact that it is not normally distributed and that not all samples have the same sampling effort. As such, we used a generalized linear model using a negative binomial error distribution, a log link and included the sampled area as an offset term. For each species $s$ caught in sample $i$ in the unstructured littoral data and the pelagic data we used the following model:

$\log \left(\right.$ abundance $\left._{s, i}\right)=\alpha_{s}+\beta_{s, y}+\beta_{s, d}+\varepsilon_{s}$, where $\alpha_{s}$ is the intercept associated with day abundance in the first year of sampling, $\beta_{s, y}$ is/are the slope(s) associated with day abundance in subsequent year(s), $\beta_{s, d}$ is the slope associated with night abundance, and $\varepsilon_{s}$ is a negative binomial error term. The $P$ value of parameter $\beta_{s, y}$ indicates whether the year effect is significant and the $P$-value of parameter $\beta_{s, d}$ indicates whether the diel period effect is significant.

EF was conducted only in 2011 but covered all littoral habitats, so a habitat effect must be included to estimate diel differences. Similarly, we used the following model to analyze the EF data:

$\log \left(\right.$ abundance $\left._{s, i}\right)=\alpha_{s}+\beta_{s, h}+\beta_{s, d}+\varepsilon_{s}$

The $P$-value of parameter $\beta_{s, h}$ indicates whether the habitat effect is significant and the $P$-value of parameter $\beta_{s, d}$ indicates whether the diel period effect is significant. The estimated value of parameter $\beta_{s, d}$ in Eqs. (1) and (2) also indicates whether fish abundance increases (if parameter $\beta_{s, d}$ has a positive value) or decreases (if parameter $\beta_{s, d}$ has a negative value) at night.

We then pooled the beach seine and trawl data to estimate changes in fish density between diel periods (night vs. day) and between habitats (littoral vs. pelagic zone) concurrently. The definition of sampling area for EF is rather difficult (Reynolds, 1996) and therefore the test of difference between EF densities and trawl/purse seine net densities could not be performed.

A generalized linear model linking observed fish density and the variables of interest is used to obtain parameter estimates that demonstrate whether day and night densities differ between the littoral and the pelagic zones. The model uses a negative binomial error structure, a log link and the sampled area as an offset term. The model is formulated as

$\log \left(\right.$ abundance $\left._{s, i}\right)=\alpha_{s}+\beta_{s, d}+\beta_{s, h}+\beta_{s, d h}+\varepsilon_{s}$,

where $\alpha_{s}$ is the overall intercept representing fish abundance in the littoral during the day, $\beta_{s, d}$ is the diel period slope associated with fish abundance in the littoral at night, $\beta_{s, h}$ is the habitat slope associated with fish abundance in the pelagic zone during the day, and $\beta_{s, d h}$ is the slope associated with fish abundance at night in the pelagic zone. The term $\varepsilon_{s}$ represents a 
negative binomial error distribution. The model is applied to the dominant ecospecies sampled in the reservoir and provides interpretable parameter estimates that can distinguish whether species undergo NIM (positive and statistically significant value of $\beta_{s, h}$ ) or NOM (positive and statistically significant value of $\left.\beta_{s, d h}\right)$.

Some species were not caught at all in certain diel periods and habitats which hindered model fitting. We also wanted to ascertain the robustness of our findings, so we used a ratio-based method to evaluate diel changes in fish density. We converted the catch abundance into a catch rate by dividing the catch by the sampled area (catch-per-unit-of-effort, CPUE). We used a logarithmic transformation [ $\log (\mathrm{C}$ PUE +2$)$ ] to compute the night to day ratio (N/D ratio) for each site that were sampled during the day and the following night. We then estimated the significance of year and habitat effects using the following linear models:

$$
\begin{aligned}
& \log \left(\mathrm{CPUE}_{s, i}^{n}+2\right) / \log \left(\mathrm{CPUE}_{s, i}^{d}+2\right) \\
& \quad=\alpha_{s}+\beta_{s, y}+\beta_{s, d}+\varepsilon_{s} \\
& \log \left(\mathrm{CPUE}_{s, i}^{n}+2\right) / \log \left(\mathrm{CPUE}_{s, i}^{d}+2\right) \\
& \quad=\alpha_{s}+\beta_{s, h}+\beta_{s, d}+\varepsilon_{s},
\end{aligned}
$$

where $\mathrm{CPUE}_{s, i}^{n}$ is the night CPUE of species $s$ caught in sample $i, \mathrm{CPUE}_{s, i}^{d}$ is the day CPUE. The other parameters are as per Eqs. (1) and (2) except that $\varepsilon_{s}$ is a Gaussian error term $\left[\varepsilon_{s} \sim N(0,1)\right]$. Equation (4) was used for trawl and purse seine data and Eq. (5) was used for EF data.

The models described by Eqs. (1) and (2) also allowed us to estimate the diel changes in the density of predator species such as pikeperch, asp Leuciscus aspius (L.), pike Esox lucius (L.), large perch (>150 mm), wels Silurus glanis L. and eel. We also compared the size distribution of pikeperch and asp captured by beach seining and EF in the littoral to the size distribution of individuals from pelagic zone sampled by trawl and purse seine using a two-sample Kolmogorov-Smirnov test.

To reveal a potential switch of feeding habitat between day and night, a comparison of fish gut fullness (stomach fullness for ruffe) was performed. This parameter was compared between habitats (unstructured littoral and pelagic zone) and diel periods. Only the first part of the gut (or only the stomach for ruffe) was chosen for fullness comparisons because it provided the best evidence of fish feeding in those habitats at the time of sampling (Vašek \& Kubečka, 2004). The test was done separately for each species, and bream and roach were divided into two age categories, age $1+$ fish and fish older than $1+$, prior to analysis. The analysis had two factors-period and habitat. While the data were not normally distributed, the large number of dissected fish in each category allowed the use of a parametric two-way ANOVA (Sokal \& Rohlf, 2012).

The comparison of Daphnia density among all littoral habitats as well as the pelagic zone was performed separately for each year using the nonparametric Kruskal-Wallis test.

All statistical analyses were conducted using the $\mathrm{R}$ software (R Core Team, 2013).

\section{Results}

A total of 16,634 individual fish from 18 species (older than age $0+$ ) were caught in the Rímov Reservoir during the study period. Cyprinids and percids were the dominant families in both the littoral and pelagic zones during all years (Appendix 1 in ESM).

Unstructured beach habitat (beach seining)

The unstructured beach habitat was mostly occupied at night (Fig. 2). Night densities were significantly higher for all groups of bream and roach as well as large bleak, small perch, pikeperch and ruffe, and the total average density per haul (Table 2). None of the species had a significantly higher density during the day. The N/D ratio significantly differed between the years only for middle and large bream (Table 2). However, the N/D ratio was on average considerably higher than one in the ecospecies in both years. Therefore, their higher night occurrence in this habitat was consistent in both years (Table 3).

\section{All littoral habitats (electrofishing)}

The many occurrences of zeroes during day sampling impaired the fitting of the model defined in Eq. (2) for middle bream, large roach, large bleak, large perch, asp, pikeperch, rudd Scardinius erythrophthalmus (L.), and ruffe. In spite of that, consistent night density 
Fig. 2 Comparison of day (gray color) and night (black color) densities (each boxplot shows the 25 th, 50th, and 75th quantile and outliers) of dominant ecospecies and species in a the unstructured beach habitat sampled using a beach seine net in 2009, 2010, and 2011 and in $\mathbf{b}$ the pelagic sampled by trawl and purse seine net in 2010 and 2011

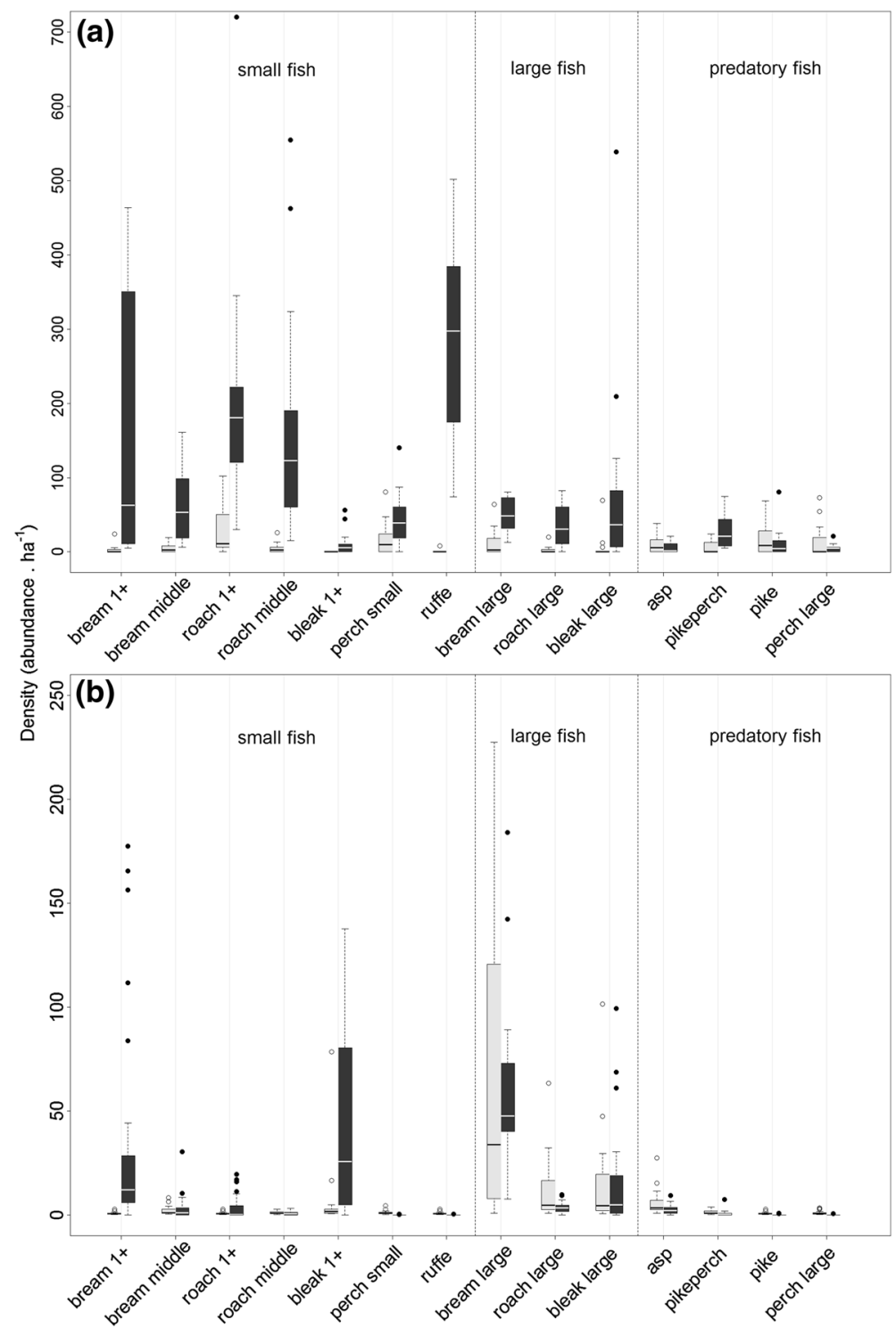

increase in all tested habitats was found for small bream, large bream, small roach, middle roach, pike, and for the total average density per sample (Table 2; Fig. 3). No species had a significantly higher density during the day. The habitat had a significant influence on the catch of $1+$ bream, $1+$ roach, middle roach, small perch, and the total density per sample. 1+ bream had a higher density in the beach habitat whereas both small and middle roach had a higher density in stump habitat (Table 2; Fig. 3). The total abundance per sample was lower in the rubble habitat than in the other habitats (Table 2 and 3). The N/D ratio significantly varied among habitats only for $1+$ bream, middle roach, and for total average density (Tables 2,3). The increase in night densities of both ecospecies was higher in the beach and stumps habitats than in the rubble habitat (Table 2; Fig. 3).

Pelagic zone (trawling and purse seining)

$1+$ bream and $1+$ roach were missing in the day samples (only one specimen of $1+$ bream and not a 
Table 2 Significance of each tested factor for the density of dominant ecospecies and species separately for the unstructured beach habitat (US beach) sampled using beach seine net
(BS), all littoral habitats sampled using electrofishing (EF) and pelagic sampled using trawl and purse seine net

\begin{tabular}{|c|c|c|c|c|c|c|c|c|c|}
\hline & \multicolumn{3}{|c|}{ US beach (BS) } & \multicolumn{3}{|c|}{ All lit. hab. (EF) } & \multicolumn{3}{|c|}{ Pelagic zone } \\
\hline & Period & Year & $\begin{array}{l}\text { N/D r.* } \\
\text { year }\end{array}$ & Period & Habitat & $\begin{array}{l}\text { N/D r.* } \\
\text { habitat }\end{array}$ & Period & Year & $\begin{array}{l}\text { N/D r.* } \\
\text { year }\end{array}$ \\
\hline Bream 1+ & Night $* * *$ & $2009 * * *$ & NS & Night $* * *$ & $\begin{array}{l}\text { L rubble***, } \\
\text { L stumps* }\end{array}$ & $\mathrm{L}_{\text {rubble** }}$ & NA & NA & $\mathrm{H} 2011 * *$ \\
\hline Bream middle & Night $* * *$ & $\begin{array}{r}2009 \\
\text { NS }\end{array}$ & Year* & NA & NA & NS & Night*** & NS & $\begin{array}{l}\mathrm{H} \\
2010 * * *\end{array}$ \\
\hline Bream large & Night $* * *$ & $2009 *$ & Year** & Night* & NS & NS & NS & $\begin{array}{c}\mathrm{L} 2010 * *, \mathrm{~L} \\
2011 * * *\end{array}$ & NS \\
\hline Roach 1+ & Night $* * *$ & $\begin{array}{r}2009 \\
\text { NS }\end{array}$ & NS & Night*** & $\begin{array}{c}\mathrm{L} \text { rubble*, } \mathrm{H} \\
\text { stumps } * * *\end{array}$ & NS & NA & NA & $\begin{array}{l}\mathrm{H} \\
2011 * * *\end{array}$ \\
\hline Roach middle & Night $* * *$ & $2009 *$ & NS & Night $* * *$ & H stumps $* * *$ & L rubble* & Night $* * *$ & NS & NS \\
\hline Roach large & Night $* * *$ & $\begin{array}{r}2010 \\
\text { NS }\end{array}$ & NS & NA & NA & NS & NS & L 2011* & NS \\
\hline Bleak 1+ & NA & NA & NS & NS & NS & NS & Night $* * *$ & NS & NS \\
\hline Bleak large & Night $* * *$ & $2009 * * *$ & NS & NA & NA & NS & NS & L 2011*** & NS \\
\hline Perch $<150 \mathrm{~mm}$ & Night** & $2010 * *$ & NS & NS & H stumps* & NS & NA & NA & H 2011* \\
\hline Perch $>150 \mathrm{~mm}$ & NS & $2009 * *$ & NS & NA & NA & NS & NS & NS & NS \\
\hline Asp & NS & $2009 *$ & NS & NA & NA & NS & NS & H $2010 * * *$ & NS \\
\hline Pikeperch & Night $* * *$ & $2009 * *$ & NS & NA & NA & NS & NS & NS & NS \\
\hline Pike & NS & $2010 * * *$ & $\mathrm{NS}$ & Night $* * *$ & NS & NS & - & - & - \\
\hline Rudd & NS & $\begin{array}{r}2010 \\
\text { NS }\end{array}$ & NS & NA & NA & NS & NA & NA & NS \\
\hline Ruffe & Night $* * *$ & $2009 * * *$ & NS & NA & NA & NS & NA & NA & NS \\
\hline Average density & Night $* * *$ & $2009 * * *$ & NS & Night $* * *$ & $\begin{array}{l}\text { L rubble**, H } \\
\text { stumps* }\end{array}$ & L rubble* & NS & H 2011* & $\begin{array}{l}\mathrm{H} \\
2011 * * *\end{array}$ \\
\hline
\end{tabular}

Factors tested in the unstructured beach habitat (US beach) and the pelagic zone were: diel period, year and interaction between the N/D ratio and year. Factors tested in the all littoral habitats were: diel period, habitat and interaction between the N/D ratio and habitat. Diel period (night), year, littoral habitat, or zone (pelagic or littoral zones) in which the density of certain species/ecospecies was significantly higher $(\mathrm{H}-$ only in factors year and habitat) or lower ( $\mathrm{L}$-only in factors year and habitat) are given with asterisks indicating the degree of significance ( $* P \leq 0.05$, ** $P \leq 0.01$, *** $P<0.001)$. NS means no significant difference. Inappropriate model fits were not included and are identified by NAs (not applicable)

single $1+$ roach was captured during the day for the whole three-year study period) and appeared only in night samples (Appendix 1 in ESM; Fig. 2). Such data distribution resulted in inappropriate fits of the model defined in Eq. (3). Significant higher densities were found at night for middle bream and roach and small bleak (Table 2; Fig. 2). No species had higher density during the day (Table 2). The N/D ratio significantly differed throughout the study years for $1+$ and middle bream, $1+$ roach and small perch. The N/D ratio was on average considerably higher than one for $1+$ and middle bream and $1+$ roach, throughout the whole three-year study period and the observed year-to-year differences were due to the different numbers of fish captured in different years (Table 3). However, the N/D ratio was below or equal to one for small perch suggesting higher day densities in trawl catches (Appendix 1 in ESM; Table 3).

Unstructured beach habitat (beach seining) versus pelagic zone (trawl, purse seine)

The model defined in Eq. (3) provides parameter estimates that simultaneously identify the densities in 
Table 3 The average N/D ratio between night and day densities of dominant ecospecies and species counted separately for each year/habitat in the unstructured beach habitat
(US beach) sampled using beach seine net (BS), all littoral habitats (All lit. hab.) sampled using electrofishing (EF) and the pelagic sampled by trawl and purse seine net

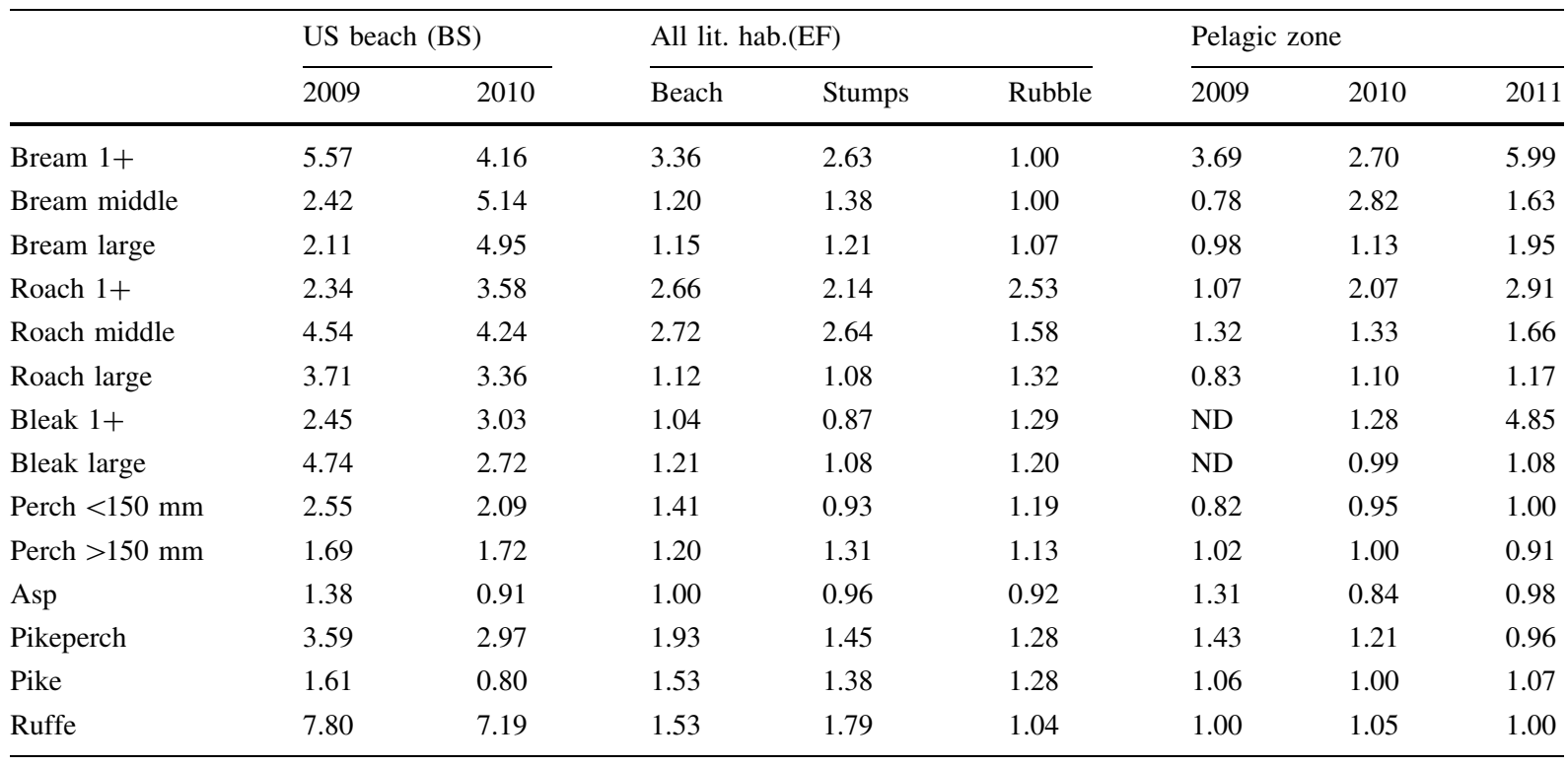

ND means no data. The N/D ratio in value of one means equal catch in both periods, under one higher catch at day, more than one higher catch at night
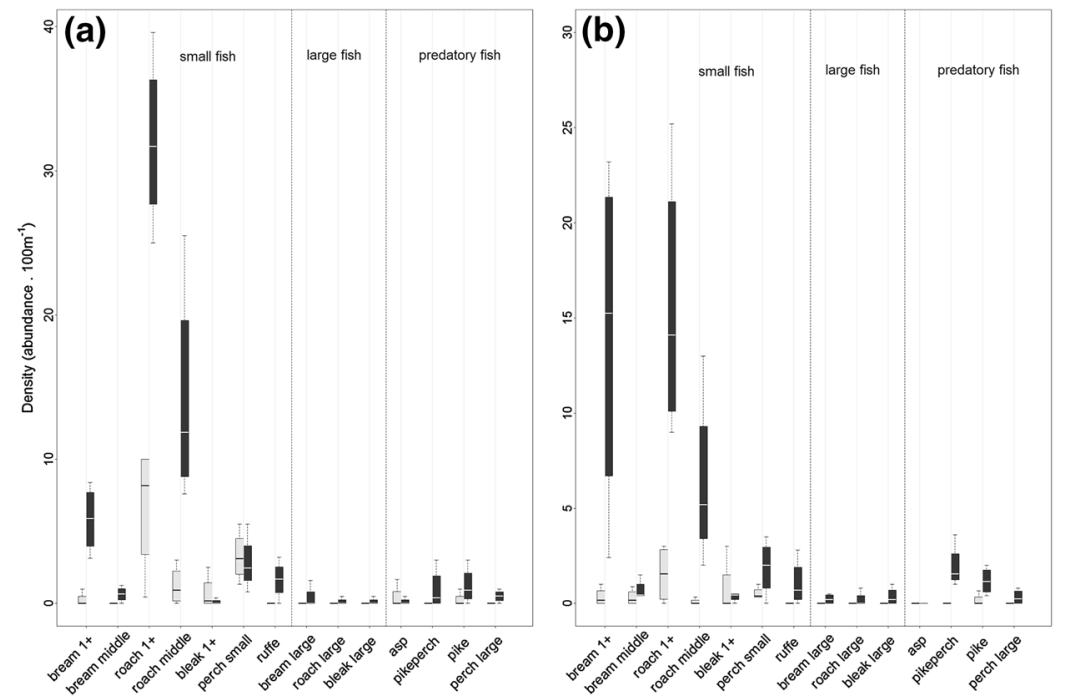

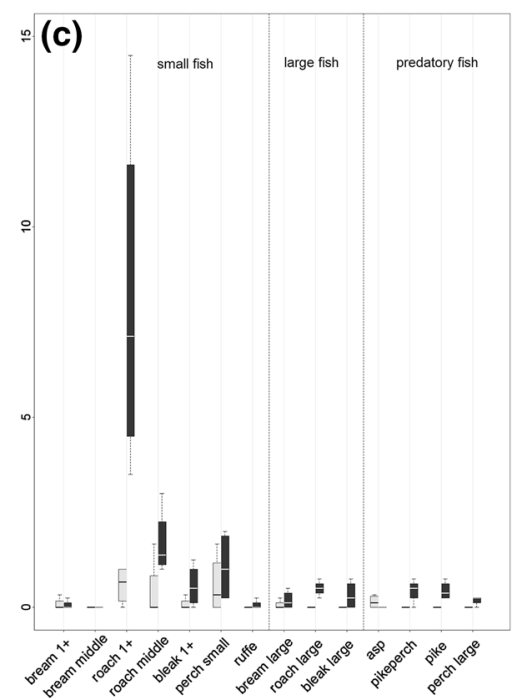

Fig. 3 Comparison of day (gray color) and night (black color) mean densities (means are indicated by bars, standard deviations are indicated by whiskers) of dominant ecospecies and species in different littoral habitats sampled using electrofishing in the year 2011 (a stumps, b beach, c rubble) both littoral and pelagic zones and in both diel periods. Because of the complete absence of certain species in some habitat/diel period combinations, the model fitting was problematic for small bream, small roach, small bleak, pike, and ruffe. For the other species, however, the parameter estimates indicated a significant increase in fish density at night in the littoral for large bream, middle roach, large roach, large bleak, 
small perch, and pikeperch (Table 4). The day density in the pelagic zone was lower than in the littoral for middle bream, middle roach, small perch, large perch, pikeperch, and rudd. An increase in the pelagic density at night was observed for middle bream, middle roach, large roach, and pikeperch whereas large bream, middle bleak, small perch, large perch, and rudd had higher pelagic densities during the day.

The simultaneous comparison of habitat and diel period revealed that the increase in littoral density at night for both large roach and large bleak exceeded the higher density observed in the pelagic zone during the day. That is, the day density of both species was higher in the pelagic zone than in the littoral but the night density in the littoral exceeded the observed day or night density in the pelagic zone (Table 4).

\section{Predators}

The dominant fish predators were asp, pikeperch, pike, and large perch (Appendix 1in ESM). Littoral densities of pike were significantly higher at night than during the day (Table 2). In the pelagic zone the species was virtually absent (only three individuals were captured over the whole three-year study period). Pikeperch densities were higher in all littoral habitats at night than during the day whereas no diel difference in densities was found in the pelagic zone (Fig. 2;
Table 2). This increase in pikeperch densities in the littoral at night resulted in densities that were two orders of magnitude higher in the unstructured littoral than in the pelagic zone at night (Appendix 1 in ESM; Table 4). A comparison of pikeperch size distributions between pelagic and littoral zones revealed significant differences in these zones during both diel periods (Kolmogorov-Smirnov test, $P<0.05$ for both diel periods). Subadult pikeperch prevailed in the littoral assemblage and almost no pikeperch smaller than $200 \mathrm{~mm}$ (SL) were captured in the pelagic zone (Fig. 4). Asp and large perch densities did not differ between diel periods or between zones (Table 4). However, the size distribution of asp differed between the littoral and pelagic zones similarly to that of pikeperch. That is, individuals smaller than $200 \mathrm{~mm}$ (SL) prevailed in littoral catches whereas larger individuals mostly occurred in the pelagic catches (Kolmogorov-Smirnov test, $P<0.05$ in both diel periods; Fig. 4).

Gut fullness, diet consumption, and Daphnia density

For all groups of bream, bleak, and roach that we tested, we observed a trend in gut fullness. The fullness of the first part of the gut was significantly lower at night than during the day (Table 5). This part
Table 4 Fitted parameter values of the model concurrently estimating the effects of diel period and littoral/pelagic habitat [Eq. (3) in the main text]

Parameter estimates represent the logarithmic density of fish species in each habitat and diel period. Statistical significance is indicated at the $P \leq 0.05$ (*), $P \leq 0.01(* *)$ and $P<0.001(* * *)$

\begin{tabular}{|c|c|c|c|c|}
\hline & $\begin{array}{l}\text { Littoral day } \\
\left(\alpha_{s}\right)\end{array}$ & $\begin{array}{l}\text { Littoral night } \\
\left(\beta_{s, d}\right)\end{array}$ & $\begin{array}{l}\text { Pelagic z. day } \\
\left(\beta_{s, h}\right)\end{array}$ & $\begin{array}{l}\text { Pelagic z. night } \\
\left(\beta_{s, d h}\right)\end{array}$ \\
\hline Bream 1+ & -1.027 & $4.839 * * *$ & -23.686 & $3.504 * * *$ \\
\hline Bream middle & -0.257 & $2.503 * * *$ & $-1.351 *$ & 0.316 \\
\hline Bream large & 0.516 & $1.454 * * *$ & $2.198 * * *$ & $2.438 * * *$ \\
\hline Roach 1+ & $1.492 * * *$ & $1.989 * * *$ & -30.205 & $-1.29 * *$ \\
\hline Roach middle & -0.338 & $3.605 * * *$ & $-2.426 * * *$ & -0.853 \\
\hline Roach large & $-0.886^{*}$ & $2.555 * * *$ & $1.445^{* *}$ & $1.12 *$ \\
\hline Bleak 1+ & NA & NA & NA & NA \\
\hline Bleak large & 0.004 & $2.539 * * *$ & 1.158 & $1.366^{*}$ \\
\hline Perch $<150 \mathrm{~mm}$ & $0.926 * *$ & $0.839 *$ & $-3.282^{* * *}$ & $-5.008 * * *$ \\
\hline Perch $>150 \mathrm{~mm}$ & 0.559 & -0.831 & $-3.469 * * *$ & $-4.529 * * *$ \\
\hline Asp & 0.309 & -0.49 & -0.165 & -0.417 \\
\hline Pikeperch & -0.132 & $1.442 * *$ & $-1.923 * * *$ & $-1.222 * *$ \\
\hline Pike & NA & NA & NA & NA \\
\hline Rudd & 0.836 & 0.197 & $-3.911 * * *$ & $-4.392 * * *$ \\
\hline Ruffe & NA & NA & NA & NA \\
\hline
\end{tabular}


Fig. 4 The comparison of littoral (all sampled habitats) and pelagic size distribution of $\mathbf{a}$ pikeperch and $\mathbf{b}$ asp captured in both diel periods

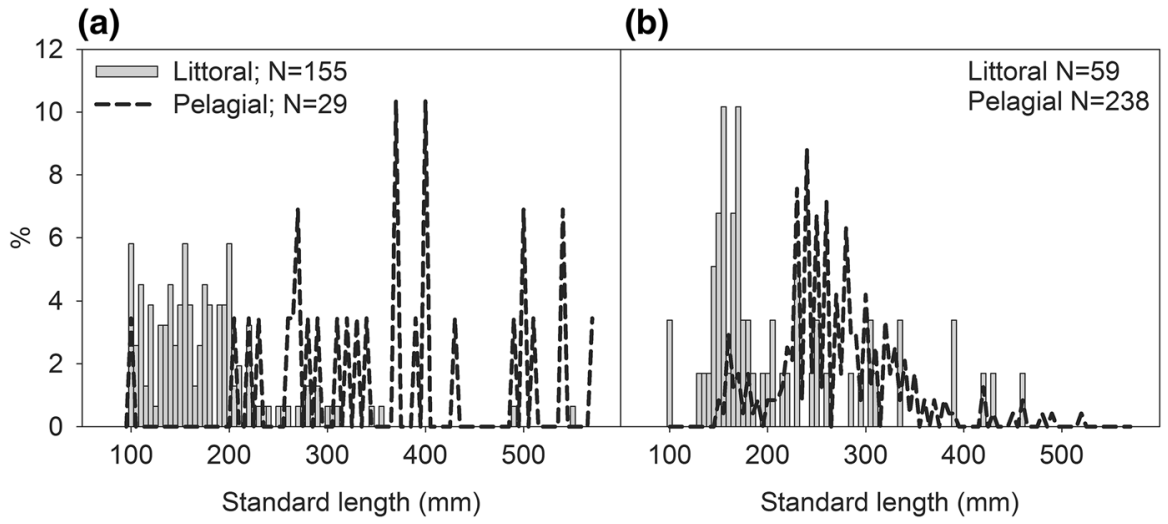

of the gut was almost empty in the majority of fish caught at night (Fig. 5). The proportion of fish with a gut fullness code value of one and higher ( $>25 \%$ full) ranged from 3.6 to $6 \%$, with the exception of large bream in which it was $20 \%$ (Table 5). In other words, the average fullness of the first part of the gut was very low for all species at night, ranging only from 0.06 (bleak) to 0.58 (large bream). Difference of fullness between the first and the other gut parts followed a similar trend in all ecospecies at night. Fullness gradually increased from the lowest value in the first part of the gut to the highest value in the third part (Table 5). During the day, the average fullness of the first gut part varied among species, with the highest fullness observed for large roach and bleak (Table 5; Fig. 5). Ruffe gut fullness could not be compared between littoral and pelagic zones or between diel periods since the species was only captured in the littoral at night. In contrast to the other species, ruffe stomach and gut fullness was very high in the littoral at night (Table 5; Fig. 5).

Zooplankton was the dominant prey for both age groups of bream in both the littoral and pelagic zones and diel periods, with the exception of $1+$ bream captured during the day in the littoral in which insect larvae dominated. Benthic prey and terrestrial insects were the dominant prey of $1+$ roach in the littoral, whereas zooplankton was the dominant food of large roach in the pelagic zone during both periods and in the littoral at night. The diet of large roach captured in the littoral during the day was dominated by benthic insects, mainly larvae of Chironomidae and Trichoptera. The diet composition of bleak differed between diel periods but not between zones. Zooplankton highly dominated bleak diet during the day, whereas benthic and terrestrial insects dominated at night. Ruffe diet consisted mainly of benthic insects (Chironomidae, Trichoptera, and Ephemeroptera larvae) and zooplankton (Fig. 5).

The density of Daphnia was significantly higher in the unstructured littoral (beach) than in the pelagic zone during the year 2009 (Kruskal-Wallis test, $P<0.05$; Fig. 6). In 2011, Daphnia density was higher in the beach habitat than elsewhere, but the difference was not significant $(P=0.092$; Fig. 6). Daphnia density was considerably higher in the year 2009 than in the year 2011 (Fig. 6).

\section{Discussion}

Extensive multi-gear sampling of the littoral and pelagic zones of the Rímov Reservoir revealed diel changes in fish distribution that were consistent from year to year. The observed changes were highly ageand species-dependent and only partially corroborated the postulated hypotheses of NOM and NIM distribution patterns. The key to understanding the observed diel changes in fish distribution is to appropriately determine the links between fish density and the availability of food in the different habitats sampled and to the predatory pressures facing the fish under study. We will now examine our results in light of these competing hypotheses and will identify how the different ecospecies under scrutiny follow expected patterns.

Small- and medium-sized ecospecies (further referred as "subadults") mostly avoided the pelagic zone and unstructured littoral during the day and occupied these zones exclusively or predominantly at 
Table 5 Gut fullness and variability of the fullness (standard deviation SD) given separately for the three parts of the gut (cyprinids) and stomach and gut of ruffe

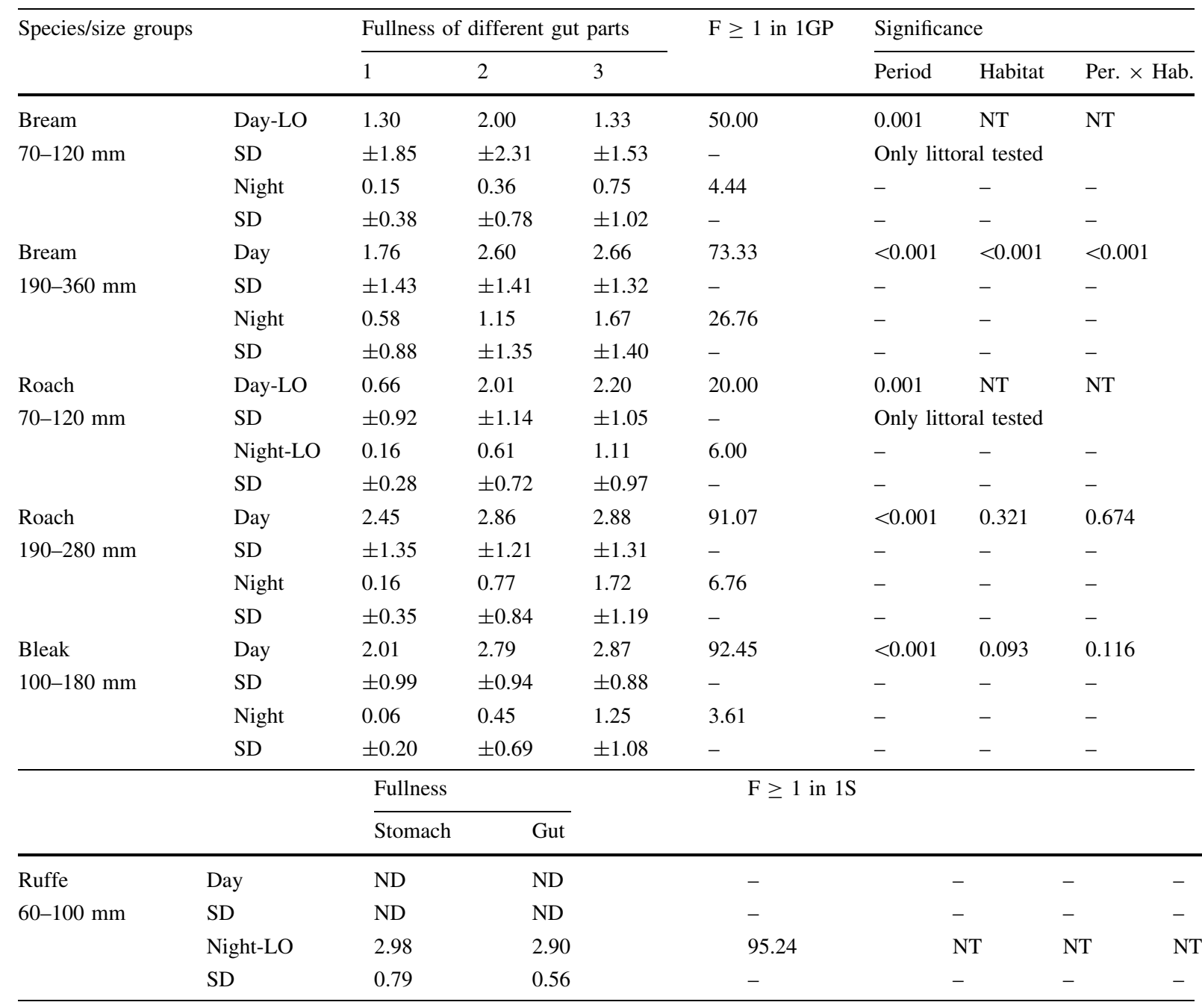

Fullness from pelagic and unstructured littoral habitats was pooled and is given separately for each diel period. LO means only littoral and indicate cases when no fish of a group was detected in the pelagic and no pooling was done. " $F \geq 1$ in $1 \mathrm{GP}$ " ("F $\geq 1$ in $S$ " for ruffe) indicate the proportion of fish with a fullness value of one and higher in the first part of the gut (stomach for ruffe) and is expressed as a percentage (\%). In addition, the significance of factors such as diel period, habitat and their influence on the fullness of the first gut part is given. ND means no data and NT not tested

night. However, the expected day association of these fish with the structured littoral was observed only for subadult roach but at densities lower than those observed in structured and unstructured littoral at night. Adult specimens of several species (bream, roach, and bleak) preferred the pelagic zone during the day and migrated to the littoral at night, thus following the expectations of NIM distribution. However, such migration was performed with various intensities among species and many individuals of bream, roach, and bleak adults did not perform migration, and remained in the pelagic zone through the night. The most dominant predators (asp, pike, and pikeperch) were present in both the littoral and pelagic zones. Asp densities did not differ between zones or diel periods, whereas pikeperch and pike occurred mostly in the 

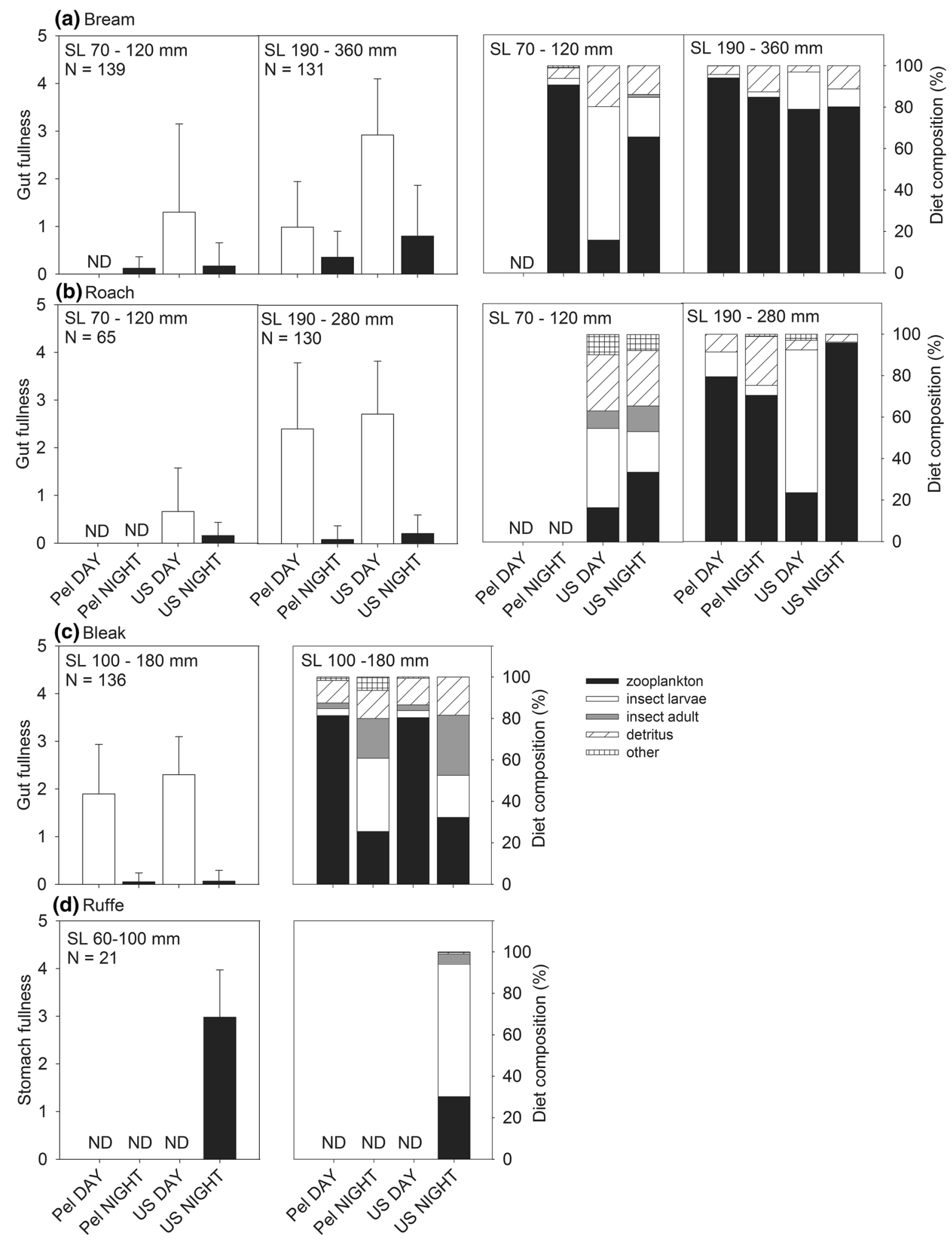
४Fig. 5 Mean gut (stomach for ruffe) fullness (left) and diet composition (right) in the first part of the gut of a bream, $\mathbf{b}$ roach c bleak, and $\mathbf{d}$ ruffe (means are indicated by boxes, standard deviations are indicated by whiskers) in the unstructured beach habitat $(\mathrm{US})$ and pelagic zone ( $\mathrm{Pel}$ ) during both diel periods. $N D$ means no data and indicates cases where no fish was captured in a certain habitat and period

littoral with higher densities at night. Bream, roach, and bleak fed only during the day in both zones while intensive night feeding was found only for ruffe.

The main expectation of NOM is for small zooplanktivorous fish to be associated with littoral shelters to avoid predators during the day and to migrate toward the pelagic zone at night to take advantage of abundant zooplankton prey (Bohl, 1980; Romare et al., 2003; Gliwicz et al., 2006). In other words, higher densities of small zooplanktivorous fish should be found at structured littoral than at unstructured habitats (pelagic zone and unstructured habitats) during the day and the opposite pattern should be observed at night. The results of our study revealed more elaborate patterns of fish habitat occurrence and utilization for small sized than we expected.

The dominant zooplanktivorous small ecospecies in the Ŕímov reservoir were found to be subadults of roach, bream, and bleak. Day association with woody structured habitat was found only for subadult roach (age $1+$ to $3+$ ), while the occurrence of the other two ecospecies were rare in all littoral habitats during the day. Subadults of bream and roach were not detected in the pelagic zone during the day, while bleak was detected at low densities in that zone. The density of these ecospecies was higher during night than during day in almost all sampled habitats with apparent species-specific habitat preference. At night, roach densities increased mostly in littoral habitats, bleak densities increased in the pelagic habitat only, while bream densities increase in both, littoral and pelagic habitats.

The low densities detected by our sampling gears during the day suggest the existence of a daytime refuge in habitats that were not covered by our sampling. Such refuge could be deeper benthic habitats in the case of roach and bream. Our sampling did not detect these ecospecies in the pelagic zone during the day. Prchalová et al. (2009) studied fish community in the Ŕímov Reservoir using gillnets, and demonstrated the occurrence of bream and roach older than $0+$ occur at depths ranging from 0 to $10 \mathrm{~m}$ in benthic habitats. The low day densities for bleak were most likely due to the fact that they occupied the transition zone between the littoral and the pelagic zones. We base this hypothesis on a number of observations. First, 1+ bleak was detected in both the littoral and pelagic zones during the day. Second, bleak individuals from both zones were dissected and showed highly similar diet composition and gut fullness, with a dominance of zooplankton, but also included small proportion of benthic components (detritus and insect larvae). Lastly, bleak is known to have a schooling behavior, mainly during day (Bohl, 1980). The occurrence of small-sized fish schools were detected by hydroacoustic in the transition between the pelagic and the littoral zones of the Rímov Reservoir (M. Muška, pers. comm.). We assume that these schools consist mainly of bleak which utilize both the littoral and pelagic zone for feeding.

In the Rímov Reservoir, pike, large perch, and asp were the most dominant predators during the day. Pike
Fig. 6 Mean densities of Daphnia sp. in the pelagic zone and different littoral habitats (means are indicated by bars, standard deviations by whiskers) in the year a 2009 and b 2011 (a)

(b)

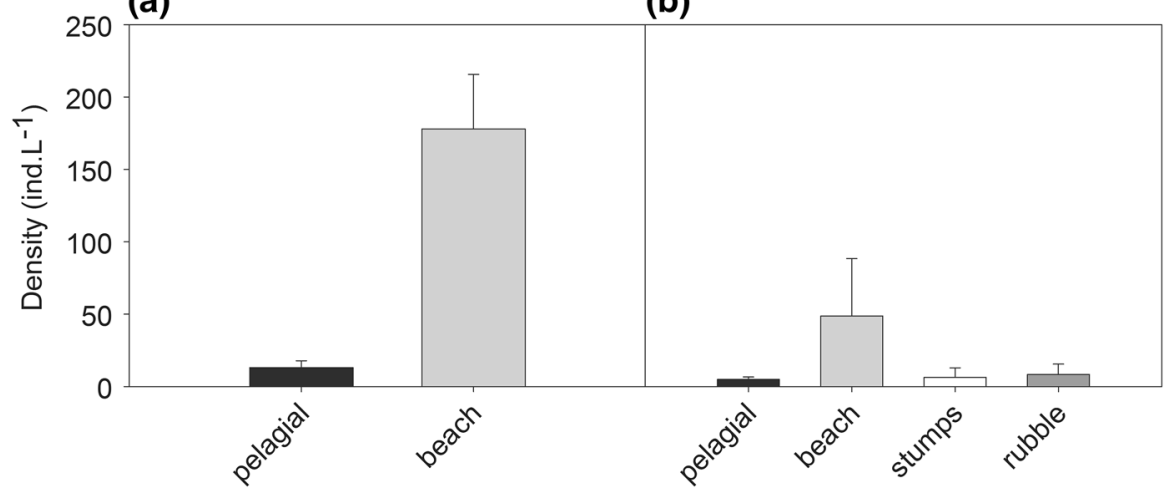


and large perch occupied the littoral, while asp was found in both the littoral and pelagic zones. All species are considered to be day or crepuscular foragers (Fredrich, 2003; Zamora \& Moreno-Amich, 2002; Jepsen et al., 2001). Pike is in particular a "sit and wait" predator (Jepsen et al., 2001), whereas perch is an actively swimming predator (Zamora \& MorenoAmich, 2002). Both species hunt mostly in near shore waters (Jepsen et al., 2001; Zamora \& Moreno-Amich, 2002). Asp is a chasing predator hunting offshore in the upper part of the water column (Lammens \& Hoogenboezem, 1991; Prchalová et al., 2009). This combination of predators suggests that both the littoral and pelagic zones have a high predation risk for small fish during the day. Structures that could be used as a shelter to reduce predation risk are not available in the pelagic zone and their occurrence in the littoral is restricted as there are no macrophytes in the reservoir and woody structures cover only $8 \%$ of the shoreline. These findings support our hypothesis that subadults of bream and roach avoid these habitats and hide in the deeper benthic habitats during the day. We may hypothesize that the behavior of $1+$ bleak; avoiding the pelagic and staying close to the safer littoral zone during day, is driven by high occurrence of their predators in the pelagic zone. High numbers of asp larger than $200 \mathrm{~mm}$ were detected in the pelagic zone at day and bleak is very important part of asp diet (Krpo-Ćetković et al., 2010).

Several studies have suggested that nocturnal predators can influence small fish distribution at night (Brabrand \& Faafeng, 1993; Hölker et al., 2007). Pikeperch was the most dominant nocturnal predator in both the littoral and pelagic zone. This species is considered a pelagic predator (Craig, 1987) that can considerably reduce the density of their prey in the pelagic zone (Brabrand \& Faafeng, 1993; Hölker et al., 2007). However, results from our study revealed that the density of pikeperch as well as small fish of various species was considerably higher in the unstructured littoral than in the pelagic zone. The high density of pikeperch observed in the littoral habitats is in line with Vašek et al. (2013), who found a higher density of pikeperch in the benthic than in the pelagic habitats in many other reservoirs. A comparison of pikeperch size distribution between the littoral and pelagic zones revealed that mainly individuals smaller than $200 \mathrm{~mm}$ occupied the littoral. Individuals larger than $200 \mathrm{~mm}$ were relatively rare, as only 47 individuals were captured during whole study period at night: 28 individuals in the littoral and 19 individuals in the pelagic zone. Pikeperch becomes piscivorous during the first year of its life and is a gape limited predator targeting small prey throughout its life (Dörner et al., 2007). The main component of pikeperch diet was found to be ruffe and roach of all size groups and YOY pikeperch and perch in the Bautzen Reservoir (Dörner et al., 2007) or ruffe, bleak, juvenile pikeperch and small bream in Lake Balaton (Biró, 1973). Such findings can explain the migration of pikeperch to the littoral in the Rímov Reservoir, where small fish are more concentrated than in the pelagic zone. On the other hand, it suggests that the predation pressure for small fish was higher in the littoral and relatively low in the pelagic zone of the reservoir. Therefore, pikeperch is unlikely the main driver of the night distribution of small fish.

The intensive migration of subadult roach, bream, and bleak to both the pelagic and littoral zones at night suggests that these zones represent a suitable habitat. However, our investigation of their gut fullness revealed that these fish did not feed in any of these zones at night. Nevertheless, a steady increase in fullness in the second and third parts of their guts (Table 5) suggests that intensive feeding takes place before nightfall. This finding agrees with the studies of Vašek \& Kubečka (2004) and Prchalová et al. (2010). The former has shown that fish activity is highest during the twilight periods in the reservoir and the latter also documented the highest feeding rate during these periods and did not observe any feeding activity at night for subadults of these species that were captured in the pelagic zone of the reservoir. Such findings indicate that these ecospecies performed migration to the pelagic zone around sunset.

Contrary to a number of other studies (Bohl, 1980; Gliwicz \& Jachner, 1992; Gliwicz et al., 2006), all structured and unstructured littoral habitats were important for subadult roach and bream since their observed densities were considerably higher in the littoral than in the pelagic zone. This indicates the high suitability of these littoral habitats and is supported by our findings that showed higher density of Daphnia in the littoral compared to the pelagic zone. Moreover, higher densities of roach and bream subadults in the littoral could be explained not only by higher density of Daphnia in the littoral but also by high benthic food availability in this habitat. Diet of both ecospecies 
contained benthic components such as insect larvae and detritus at night. It could be hypothesized that the availability of benthic food in combination with similar or higher availability of zooplankton made the littoral a more profitable zone for those fish than the pelagic zone. However, the occurrence of subadult roach and bream in both habitats suggests that their migration is additionally driven by individual decision of particular fish, because their population was divided between open water and inshore migrants.

An important part of the littoral fish community was composed of ruffe. The species was detected only in the littoral zone at night where they intensely fed on benthic prey. The observed night activity and feeding of this species is in agreement with the studies of Jamet \& Lair (1991) and Wolter \& Freyhof (2004) that both documented similar activity and feeding patterns in the species. During scuba diving, ̌̌íha and Čech (unpublished data) observed many ruffe lying inactive on the bottom deeper than $9 \mathrm{~m}$ in the Rimov Reservoir during day. Such observation corroborate the patterns found in the Older River in Germany (Wolter \& Freyhof, 2004) and suggests that ruffe use deeper benthic habitats during the day and migrate to feed in shallower habitats at night. It seems that ruffe follow the same pattern as a small zooplanktivorous fish and avoid risky habitats during the day and utilize them only at night.

The main expectation of NIM is that fish occur in the pelagic zone during the day and migrate to the littoral zone at night. Such behavior was observed in adults of large bream, roach, and bleak. These ecospecies dominated in the pelagic zone and mostly avoided the littoral during the day. The observed day avoidance of shallow areas by large fish agrees with other studies from lakes, rivers, or reservoirs (Duncan \& Kubečka, 1995; Wolter \& Freyhof, 2004; Romare et al., 2003; Brosse et al., 2007; Erös et al., 2008) and seems to be a very common trend in freshwater ecosystems. The pelagic zone is suggested to be a more advantageous zone for large fish species because, contrary to small fish, they face a lower risk of predation in this zone (Werner et al., 1983; Lammens et al., 1992). The explanation suggested for the preference by bream and roach for the pelagic zone during day is food availability and manner of feeding. While both species are considered to be efficient benthic feeders (Lammens \& Hoogenboezem, 1991), the benthic community is poorly developed in the reservoir (J. Matěna, pers. comm.) and bream and roach feed mostly on zooplankton, especially cladocerans (Vašek et al., 2003). Our study has shown that Daphnia densities are lower in the pelagic than in the littoral zones. Such a finding could suggest that both species should be more represented in the littoral. However, previous studies (Čech \& Kubečka, 2002; Jarolím et al., 2010) have shown that both species performed sinusoidal swimming in the pelagic zone of the Římov Reservoir during the day. Such movements are beneficial for the detection of zooplanktonic prey (Daphnia and Leptodora in particular) because transparent zooplankton are better seen during the ascending and descending parts of the sinusoidal track (zooplankton is more visible against the bright light of the sky or in contrast to the dark depths). These movements could be performed only in the deeper pelagic but not in the shallow littoral zones. Thus, better visibility of zooplankton prey and generally much higher volume for food production in the pelagic zone can explain the high affinity of large bream and roach to this zone during the day. On the other hand, the variability of the N/D ratio in trawl catches of adult bream and roach, and their occasional detection in the littoral, suggest that some individuals performed excursions into the littoral during the day as well. Such visits had a feeding purpose in the case of roach, because the sampled diet of fish caught in the littoral consisted mainly of benthic prey. The intensive feeding of large bream captured in the littoral was observed as well, but even in the littoral these fish preferred zooplankton prey.

Large fish are subject to a lower predatory pressure (Brabrand \& Faafeng, 1993; Schulze et al., 2006) than small fish and are expected to undergo diel migration for feeding reasons (Schulz \& Berg, 1987; Wolter \& Freyhof, 2004). So if the driving mechanism behind their migration is food availability, we should expect the stomachs of individuals caught at night to be full. Our results indicate that feeding of roach and bleak was very low in both zones at night. Large bream feeding rate was higher at night in the littoral than in the pelagic zone, although only $26 \%$ of dissected bream individuals had fullness of their first gut part higher than one (meaning fullness higher than $25 \%$ of gut volume) and none of those breams had fullness higher than three (meaning fullness up to $75 \%$ ). This suggests that intense feeding was performed by only a small proportion (one quarter of dissected individuals) 
of bream captured in the littoral at night. This observation suggests that migration was not caused by a switching of feeding habitat for any those three species. The similar numbers of bream observed in the littoral and pelagic zone indicate that bream distribution is more homogenous at night than during the day. The species was observed to stay in schools during the day, but broke apart during sunset and fish dispersed more evenly at night (Bohl, 1980; Lyons \& Lucas, 2002). Most likely such homogenization could be the explanation for the bream density increase in the littoral of the Rímov Reservoir rather than an intentional migration there. Densities of large bleak and especially large roach were considerably higher in the littoral than in the pelagic zone, and both species seem to intentionally migrate to the littoral. Resting can be the most likely explanation for this behavior, but there is no indication why roach and bleak migrate to the littoral while the majority of bream stayed in the pelagic zone. Perhaps this is caused by speciesspecific patterns that drive their preference for the littoral (the case for roach and bleak) or pelagic zone (the case for bream), but other unknown factors could also explain this migration behavior.

There is a potential for our samples to be skewed since the gear used has been documented to have size-, species-, and light-specific selectivity biases (Bonar et al., 2009). Trawling and EF are prone to density underestimation because of gear avoidance (Reynolds, 1996; Rakowitz et al., 2012). Beach seining, however, provides relatively unbiased estimates (Pierce et al., 1990; Říha et al., 2008) when the sampled area was fully enclosed by the net. This bias is particularly noticeable during the daytime when fish trawl avoidance is higher, which can lead to an underestimation of fish density (Rakowitz et al., 2012). This bias is more pronounced for larger individuals, it is unlikely that gear avoidance will considerably bias the proportion of small size groups in the catch or the observed complete absence of small fish in the pelagic zone during the day. This notion is also supported by the findings of Muška et al. (2013) who studied the pelagic community of the Rímov reservoir using hydroacoustics. They found that fish in the pelagic zone during the day consisted mainly of individuals larger than $200 \mathrm{~mm}$ and that no fish of age $1+$ size category were present. The potential bias of EF samples is also associated with higher fish avoidance during the day (Reynolds, 1996). However, our results from EF samples favorably compare to the unbiased estimates obtained from beach seining. They both show an increase in night densities in the beach habitat. There is also no reason why EF would have different selectivity in different littoral habitats and we conclude that our results are robust and that the observed diel changes in fish density are due to changes in fish distribution and not by biases from the sampling gear.

The evaluation of fish diel distribution dynamics in light of the traditional concepts of night inshore (NIM) or offshore migrations (NOM) is not so unambiguous under the conditions observed in the Rímov Reservoir. Most likely occurrence of fish is not limited to the littoral or the pelagic zone but other habitats should be taken into consideration (Fig. 7). Movements during diel habitat change underwent in several different directions simultaneously, including inshore-offshore, offshore-inshore, but also from deeper benthic habitats to inshore or among different inshore habitats (Fig. 7). The pattern of this movement varied with species, ontogenetic development and individual decision, which should be included among important drivers of habitat preference. Obviously, there is no single ultimate reason for habitat switch. We could suggest change of predation risk and higher profitability of habitats as driver for small fish as subadults of roach, bream, bleak, or ruffe (in case of ruffe coupled with night activity). Higher profitability of inshore parts could be suggested as a reason for NIM of night predators. On the other hand, assumed drivers

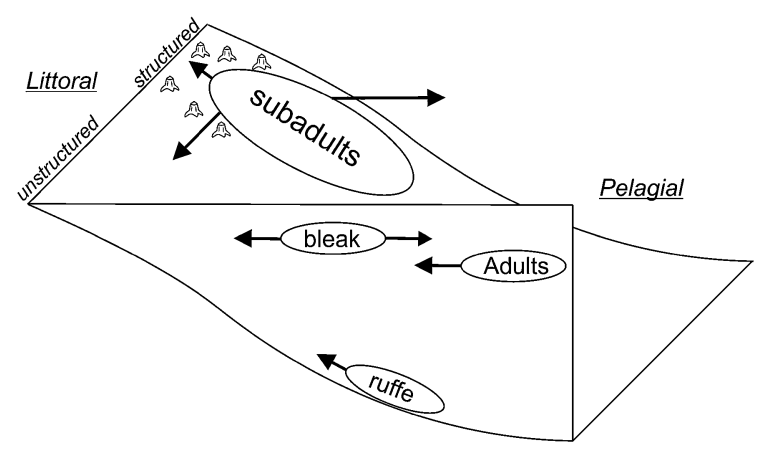

Fig. 7 Schematic representation of diel habitat preference of dominant groups of fish determined on the base of presented study. Circles stand for day habitat preference and arrows for direction of distribution at night. The subadult group involved subadults of perch, roach, and likely bream. Adults include especially large specimens of roach and bream, but likely large individuals of some other species as pikeperch could be include as well 
for NIM of bream, roach, and bleak adults as change of feeding habitat or high density of offshore predators cannot be suggested as a good explanations of diel habitat change and other better explanations should be found.

Our study is unique in its comparison of diel change of whole fish assemblage between pelagic and littoral zones, as well as between unstructured and structured littoral in the Ŕímov Reservoir. Our previous study comparing the diel change in the unstructured littoral (Říha et al., 2011) found a similar trend of occupation of this habitat in three of the four tested reservoirs, and the Rímov was one of the three with similar trends. We suggest that similar trends of fish distribution and diel dynamics as found in the present study can be applied to many other reservoirs with similar conditions in Central Europe.

Acknowledgments We would like to thank many colleagues who helped us during extensive fieldwork. We also thank three anonymous referees and the associate editor for valuable comments on the manuscript. This study was financed by project No. CZ.1.07/2.3.00/20.0204 (CEKOPOT) and DR was supported by project CZ.1.07/2.3.00/30.0032 (Promotion of post-doctoral positions in the Biology Centre of the Czech Academy of Sciences aimed to build the global competitiveness of the research teams in the Czech Republic) co-financed by the European Social Fund and the state budget of the Czech Republic.

Open Access This article is distributed under the terms of the Creative Commons Attribution License which permits any use, distribution, and reproduction in any medium, provided the original author(s) and the source are credited.

\section{References}

Biró, P., 1973. The food of pikeperch (Lucioperca lucioperca) in Lake Balaton. Annales Biology of Tihany 40: 159-183.

Bohl, E., 1980. Diel pattern of pelagic distribution and feeding in planktivorous fish. Oecologia 44: 368-375.

Bonar, S. A., W. A. Hubert \& D. W. Willis, 2009. Standard methods for sampling North American freshwater fishes. American Fisheries Society, Bethesda.

Brabrand, A. \& B. Faafeng, 1993. Habitat shift in roach (Rutilus rutilus) induced by pikeperch (Stizostedion lucioperca) introduction-predation risk versus pelagic behavior. Oecologia 95: 38-46.

Brosse, S., G. D. Grossman \& S. Lek, 2007. Fish assemblage patterns in the littoral zone of a European reservoir. Freshwater Biology 52: 448-458.

Čech, M. \& J. Kubečka, 2002. Sinusoidal cycling swimming pattern of reservoir fishes. Journal of Fish Biology 61: $456-471$.
Cerri, R. D., 1983. The effect of light-intensity on predator and prey behavior in cyprinid fish-factors that influence prey risk. Animal Behaviour 31: 736-742.

Copp, G. H. \& P. Jurajda, 1993. Do small riverine fish move inshore at night. Journal of Fish Biology 43: 229-241.

Craig, J. F., 1987. The Biology of the Perch and Related Fish. Croom-Helm, London.

Dörner, H., F. Hülsmann, F. Hölker, C. Skov \& A. Wagner, 2007. Size-dependent predator-prey relationship between pikeperch and their prey fish. Ecology of Freshwater Fish 16: 307-314.

Duncan, A. \& J. Kubečka, 1995. Land water ecotone effects in reservoirs on the fish fauna. Hydrobiologia 303: 11-30.

Erös, T., B. Toth, A. Sevcsik \& D. Schmera, 2008. Comparison of fish assemblage diversity in natural and artificial rip-rap habitats in the littoral zone of a large river (River Danube, Hungary). International Review of Hydrobiology 93: 88-105.

Fredrich, F., 2003. Long-term investigations of migratory behaviour of asp (Aspius aspius L.) in the middle part of the Elbe River, Germany. Journal of Applied Ichthyology 19: 294-302.

Gliwicz, Z. M. \& A. Jachner, 1992. Diel migrations of juvenile fish-a ghost of predation past or present. Archiv für Hydrobiologie 124: 385-410.

Gliwicz, Z. M., J. Slon \& I. Szynkarczyk, 2006. Trading safety for food: evidence from gut contents in roach and bleak captured at different distances offshore from their daytime littoral refuge. Freshwater Biology 51: 823-839.

Hladík, M. \& J. Kubečka, 2003. Fish migration between a temperate reservoir and its main tributary. Hydrobiologia 504: 251-266.

Hölker, F., H. Dorner, T. Schulze, S. S. Haertel-Borer, S. D. Peacor \& T. Mehner, 2007. Species-specific responses of planktivorous fish to the introduction of a new piscivore: implications for prey fitness. Freshwater Biology 52: 1793-1806.

Howland, K. L., M. Gendron, W. M. Tonn \& R. F. Tallman, 2004. Age determination of a long-lived coregonid from the Canadian North: comparison of otoliths, fin rays and scales in inconnu (Stenodus leucichthys). Annales Zoologici Fennici 41: 205-214.

Jacobsen, L., S. Berg, N. Jepsen \& C. Skov, 2004. Does roach behaviour differ between shallow lakes of different environmental state? Journal of Fish Biology 65: 135-147.

Jamet, J. L. \& N. Lair, 1991. An example of diel feeding cycle of 2 percids, perch (Perca fluviatilis) and ruffe (Gymnocephalus cernuus) in eutrophic Lake Aydat (France). Annales des Sciences Naturelles-Zoologie et Biologie Animale 12: 99-105.

Jarolím, O., J. Kubečka, M. Čech, M. Vašek, J. Peterka \& J. Matěna, 2010. Sinusoidal swimming in fishes: the role of season, density of large zooplankton, fish length, time of the day, weather condition and solar radiation. Hydrobiologia 654: 253-265.

Jepsen, N., S. Beck, C. Skov \& A. Koed, 2001. Behavior of pike (Esox lucius L.) $>50 \mathrm{~cm}$ in a turbid reservoir and in a clearwater lake. Ecology of Freshwater Fish 10: 26-34.

Jůza, T., M. Vašek, M. Kratochvíl, M. Čech, V. Draštík, J. Frouzová, J. Peterka, M. Prchalová, M. Říha, M. Tušer, M. Muška \& J. Kubečka, 2014. Chaos and stability of age-0 
fish assemblage in deep temperate reservoir: unpredictable success and stable behaviour. Hydrobiologia 724: 217-234.

Kratochvíl, M., Mrkvička, T., Vašek, M., Peterka, J., Čech, M., Draštík, V., Jůza, T., Matěna J., Muška M., Sed'a, J., Znachor, P., \& Kubečka, J., 2012. Littoral age 0+ fish distribution in relation to multi-scale spatial heterogeneity of a deep-valley reservoir. Hydrobiologia 696:185-198.

Krpo-Ćetković, J., A. Hegediš \& M. Lenhardt, 2010. Diet and growth of asp, Aspius aspius (Linnaeus, 1758), in the Danube River near the confluence with the Sava River (Serbia). Journal of Applied Ichthyology 26: 513-521.

Kubečka, J., 1993. Night inshore migration and capture of adult fish by shore seining. Aquaculture and Fisheries Management 24: 685-689.

Kubečka, J. \& A. Duncan, 1998. Diurnal changes of fish behaviour in a lowland river monitored by a dual-beam echosounder. Fisheries Research 35: 55-63.

Lammens, E. H. R. R. \& W. Hoogenboezem, 1991. Diets and feeding behavior. In Winfield, I. J. \& J. S. Nelson (eds), Cyprinid Fishes: Systematics, Biology and Exploitation. Chapman \& Hall, London: 353-376.

Lammens, E. H. R. R., A. Franklandman, P. J. Mcgillavry \& B. Vlink, 1992. The role of predation and competition in determining the distribution of common bream, roach and white bream in Dutch eutrophic lakes. Environmental Biology of Fishes 33: 195-205.

Lewin, W. C., N. Okun \& T. Mehner, 2004. Determinants of the distribution of juvenile fish in the littoral area of a shallow lake. Freshwater Biology 49: 410-424.

Lyons, J. \& M. C. Lucas, 2002. The combined use of acoustic tracking and echosounding to investigate the movement and distribution of common bream (Abramis brama) in the River Trent, England. Hydrobiologia 483: 265-273.

Miranda, L. E. \& M. Kratochvíl, 2008. Boat electrofishing relative to anode arrangement. Transactions of the American Fisheries Society 137: 1358-1362.

Muška, M., M. Tušer, J. Frouzová, V. Draštík, M. Čech, T. Jůza, M. Kratochvíl, T. Mrkvička, J. Peterka, M. Prchalová, M. Ř́ha, M. Vašek \& J. Kubečka, 2013. To migrate, or not to migrate: partial diel horizontal migration of fish in a temperate freshwater reservoir. Hydrobiologia 707: 17-28.

Pierce, C. L., J. B. Rasmussen \& W. C. Leggett, 1990. Sampling littoral fish with a seine-corrections for variable capture efficiency. Canadian Journal of Fisheries and Aquatic Sciences 47: 1004-1010.

Pierce, C. L., A. M. Corcoran, A. N. Gronbach, S. Hsia, B. J. Mullarkey \& A. J. Schwartzhoff, 2001. Influence of diel period on electrofishing and beach seining assessments of littoral fish assemblages. North American Journal of Fisheries Management 21: 918-926.

Prchalová, M., J. Kubečka, M. Čech, J. Frouzová, V. Draštík, E. Hohausová, T. Jůza, M. Kratochvíl, J. Matěna, J. Peterka, M. Říha, M. Tušer \& M. Vašek, 2009. The effect of depth, distance from dam and habitat on spatial distribution of fish in an artificial reservoir. Ecology of Freshwater Fish 18: 247-260.

Prchalová, M., T. Mrkvička, J. Kubečka, J. Peterka, M. Čech, M. Muška, M. Kratochvíl \& M. Vašek, 2010. Fish activity as determined by gillnet catch: a comparison of two reservoirs of different turbidity. Fisheries Research 102: 291-296.
Prchalová, M., J. Kubečka, M. Říha, M. Čech, T. Jůza, H. A. M. Ketelaars, M. Kratochvíl, T. Mrkvička, J. Peterka, M. Vašek \& A. J. Wagenvoort, 2013. Eel attacks—a new tool for assessing European eel (Anguilla anguilla) abundance and distribution patterns with gillnet sampling. Limnologica 43: 194-202.

R Core Team, 2013. R: A Language and Environment for Statistical Computing. R Foundation for Statistical Computing, Vienna, Austria.

Rakowitz, G., M. Tušer, M. Ř́ha, T. Jůza, H. Balk \& J. Kubečka, 2012. Use of high-frequency imaging sonar (DIDSON) to observe fish behavior towards a surface trawl. Fisheries Research 123-124: 37-48.

Reynolds, J. B., 1996. Electrofishing. In Murphy, B. R. \& D. W. Willis (eds), Fisheries Technique. American Fisheries Society, Bethesda: 221-254.

Říha, M., J. Kubečka, T. Mrkvička, M. Prchalová, M. Čech, V. Draštík, J. Frouzová, M. Hladík, E. Hohausová, O. Jarolím, T. Jůza, M. Kratochvíl, J. Peterka, M. Tušer \& M. Vašek, 2008. Dependence of beach seine net efficiency on net length and diel period. Aquatic Living Resources 21: 411-418.

Říha, M., J. Kubečka, M. Vašek, J. Sed'a, T. Mrkvička, M. Prchalová, J. Matěna, M. Hladík, M. Čech, V. Draštík, J. Frouzová, E. Hohausová, O. Jarolím, T. Jůza, M. Kratochvíl, J. Peterka \& M. Tušer, 2009. Long-term development of fish populations in the Rímov Reservoir. Fisheries Management and Ecology 16: 121-129.

Říha, M., J. Kubečka, M. Prchalová, T. Mrkvička, M. Čech, V. Draštík, J. Frouzová, E. Hohausová, O. Jarolím, T. Jůza, M. Kratochvíl, J. Peterka \& M. Tušer, 2011. The influence of diel period on fish assemblage in the unstructured littoral of reservoirs. Fisheries Management and Ecology 18: 339-347.

Říha, M., T. Jůza, M. Prchalová, T. Mrkvička, M. Čech, V. Draštík, M. Muška, M. Kratochvíl, J. Peterka, M. Tušer, M. Vašek \& J. Kubečka, 2012. The size selectivity of the main body of a sampling pelagic pair trawl in freshwater reservoirs during the night. Fisheries Research 127-128: $56-60$.

Roach, K. A. \& K. O. Winemiller, 2011. Diel turnover of assemblages of fish and shrimp on sandbanks in a temperate floodplain river. Transactions of the American Fisheries Society 140: 84-90.

Romare, P., S. Berg, T. Lauridsen \& E. Jeppesen, 2003. Spatial and temporal distribution of fish and zooplankton in a shallow lake. Freshwater Biology 48: 1353-1362.

Rychtecký, P. \& P. Znachor, 2011. Spatial heterogeneity and seasonal succession of phytoplankton along the longitudinal gradient in a eutrophic reservoir. Hydrobiologia 663: 175-186.

Schulz, U. \& R. Berg, 1987. The migration of ultrasonic-tagged bream, Abramis brama (L), in Lake Constance (BodenseeUntersee). Journal of Fish Biology 31: 409-414.

Schulze, T., H. Dorner, F. Holker \& T. Mehner, 2006. Determinants of habitat use in large roach. Journal of Fish Biology 69: 1136-1150.

Sed'a, J. \& M. Devetter, 2000. Zooplankton community structure along a trophic gradient in a canyon-shaped dam reservoir. Journal of Plankton Research 22: 1829-1840.

Sed'a, J., K. Kolářová, A. Petrusek \& J. Macháček, 2007. Daphnia galeata in the deep hypolimnion: spatial 
differentiation of a "typical epilimnetic" species. Hydrobiologia 594: 47-57.

Sokal, R. R. \& F. J. Rohlf, 2012. Biometry: the principles and practice of statistics in biological research, 4th ed. W. H. Freeman \& Co., New York.

Vašek, M. \& J. Kubečka, 2004. In situ diel patterns of zooplankton consumption by subadult/adult roach Rutilus rutilus, bream Abramis brama, and bleak Alburnus alburnus. Folia Zoologica 53: 203-214.

Vašek, M., J. Kubečka \& J. Sed'a, 2003. Cyprinid predation on zooplankton along the longitudinal profile of a canyonshaped reservoir. Archiv für Hydrobiologie 156: 535-550.

Vašek, M., M. Prchalová, J. Peterka, H. A. M. Ketelaars, A. J. Wagenvoort, M. Čech, V. Draštík, M. Říha, T. Jůza, M. Kratochvíl, T. Mrkvička, P. Blabolil, D. S. Boukal, J. Duras \& J. Kubečka, 2013. The ecological importance of pikeperch (Sander lucioperca L.) and other predatory fish in deep artificial systems: a comparative study of Czech and Dutch reservoirs. Ecological Engineering 52: 104-111.

Vehanen, T., J. Jurvelius \& M. Lahti, 2005. Habitat utilisation by fish community in a short-term regulated river reservoir. Hydrobiologia 545: 257-270.

Werner, E. E., G. G. Mittelbach, D. J. Hall \& J. F. Gilliam, 1983. Experimental tests of optimal habitat use in fish: the role of relative habitat profitability. Ecology 64: 1525-1539.

Wolter, C. \& J. Freyhof, 2004. Diel distribution patterns of fishes in a temperate large lowland river. Journal of Fish Biology 64: 632-642.

Zamora, L. \& R. Moreno-Amich, 2002. Quantifying the activity and movement of perch in a temperate lake by integrating acoustic telemetry and a geographic information system. Hydrobiologia 483: 209-218. 